\title{
In silico analysis and transient expression of wound-inducible promoter $M P I$ in tomato (Lycopersicon esculentum Mill. cv. CH)
}

\author{
Zahra Hajiahmadi ${ }^{1}$, Reza Shirzadian-Khorramabad ${ }^{* 1}$, Mahmood Kazemzad ${ }^{2}$, Mohammad Mahdi \\ Sohani $^{1}$
}

\author{
${ }^{1}$ Plant Biotechnology Department, Faculty of Agricultural Sciences, University of Guilan, Rasht, P.O.Box \\ 4199613776, Iran \\ ${ }^{2}$ Department of Energy, Materials and Energy Research Center, P.O. Box 14155-477, Tehran, Iran
}

*Corresponding author: r.shirzadian@guilan.ac.ir

\begin{abstract}
Various genetic promoters are applied to generate transgenic plants. Constitutive promoters such as CaMV35S are mostly being used; however, the constitutive expression of a gene could be harmful and lead to many changes in plant metabolism, growth and development. Subsequently, using inducible promoters in plant transformation has become more useful. In this project, efficiency of the wound-inducible promoter of Maize Proteinase Inhibitor (MPI) in tomato Lycopersicon esculentum Mill. cv. $\mathrm{CH}$, as a new genetic background, was investigated. Therefore, the MPI was amplified following insertion into pTZ57R/T, sequencing and subsequently ligation into binary vector pBI121. Recombinant plasmids were transferred into Agrobacterium tumefaciens AGL1 strain. The results of in silico sequence analysis of MPI specified methyl jasmonate (MeJA) and abscisic acid (ABA) as responsive motifs, which might play a role in wound signaling pathway. Therefore, tomato leaves were transformed by PBI:MPI:GUS using agroinfilteration approach following GUS expression analysis by applying histochemical GUS and qRT-PCR assays. Our results demonstrated that induction of the MPI promoter only occurred in the wounded leaves and not detected in the control leaves. GUS transcripts in the wounded leaves containing MPI promoter were 4.1 folds higher than those containing CaMV35S, and GUS histochemical assays also revealed that the MPI give higher color intensity (2.64 folds) compared to the CaMV35S. Thus, the MPI could be considered as an acceptable working and inducible promoter to generate dicot transgenic plants harboring insecticidal genes such as different types of cry genes, which just expressed when plants are being attacked by pests.
\end{abstract}

Keyword: GUS reporter, MPI, Tomato, Wound inducible promoter.

Abbrevation: ABA_Abscisic acid; CaMV35S_Cauliflower mosaic virus 35S; JA_Jasmonate; MeJA_Methyl jasmonate; MPI_Maize Proteinase Inhibitor; PBS_Phosphate buffered saline, Ubi_Maize ubiquitin.

\section{Introduction}

Many foreign genes have been introduced into plant genomes. Constitutive promoters such as cauliflower mosaic virus 35S (CaMV35S) and maize ubiquitin (Ubi) have been widely used in various plant genetic engineering approaches. The constitutive expression of a gene is harmful to their host and lead to several changes in plant metabolism as well as plant growth and development. For instance in absence of biotic stresses, it can sometimes cause metabolic drain (Zhang et al., 2013). Constitutive expression of genes is normally unregulated; therefore, take a lot of energy for their transcription and translation. Therefore, it is much more efficient if expression of a foreign gene just occurs when the gene product is needed. The constitutive expression of promoters cause presence of transgenic protein in all tissues at all stage of growth and development. It is much more acceptable to limit transgene transcription to only target tissues (Breitler et al., 2001; Andow and Ives, 2002; Bates et al., 2005; et al., 2001; Kim et al., 2008). The CaMV35S promoter has been widely used in Bt crops and after two decades, cultivation of these crops has been questionable due to the increase of pest resistance (Gassmann et al., 2011; Tabashnik et al., 2013; Van den Berg et al., 2013). Using CaMV35S promoter in production of transgenic plants has also provided concerns regarding the food safety of genetically modified plants (Kuiper et al., 2001; Shelton et al., 2002; Conner et al., 2003). Hence, it might be desirable to use inducible or tissue-specific promoters such as RSRE (general stress- inducible promoter) (Zhang et al., 2013). Therefore, use of wound-inducible promoters, which drive expression of genes encoding insecticidal proteins such as various types of CRY proteins, could be more practical to keep plants in normal growth, development as well as saving their energy in absence of biotic stress. In addition to the aforementioned advantages, the expression of transgenes should occur after pest attack in order to reduce likely unwanted effects on non-target organisms. Therefore, using wound-inducible promoter could be an important strategy and be helpful for insect resistance management strategies.

Plants have developed diverse physiological and biochemical mechanisms as defense systems against insects, pests and pathogens. These mechanisms are reinforcement of cell wall, limitation of cell energy consumption (translation arrest of some nuclear-encoded photosynthetic genes) and activation of defensive compounds (synthesis of chitinase, glucanase, phytoalexine, amylase inhibitor and serine proteinase inhibitor). Among a large number of proteins induced by wounding, plant serine proteinase inhibitors are particularly actived against insect pests and herbivores and can inhibit animal and microbial proteinase, (Heitz et al., 1999; Stotz et al., 1999; Hartl et al., 2011; Jamal et al., 2013). 
A cDNA encoding a serine proteinase inhibitor of maize (MPI) has been isolated from maize in 1994 (Cordero et al., 1994). It has been reported that the mpi is locally and systematically inducible by mechanical and fungal wounding as well as treatment by methyl jasmonate (MJ) and abcisic acid (ABA). Moreover, it has been shown that $689 \mathrm{bp}$ upstream to $197 \mathrm{bp}$ downstream region of start site of $m p i$ is responsive to wounding (Breitler et al., 2001), meaning that this region could be probably used as a wound-inducible promoter. Consequently, the efficiency and performance of MPI promoter has been investigated in tomato as a model plant for dicot species.

Transient expression of foreign genes in plant tissues is a valuable and functional method for investigating gene function in a short time period with low expenses (Yang et al., 2000). This method is simple, rapid and there's no need for any specialized equipment. In this regards, agroinfilteration is an in planta method to analyze gene function. In this approach, the Agrobacterium suspension harboring gene of interest is injected into plant leaves using a needle-free syringe. After 3-7 days (in order to integrate foreign gene in plant genome), expression of interesting genes can be investigated without costly equipments and complicated methods. In this system, bacteria suspension normally enters leaves through stomata following T-DNA transfer to nucleus. Agroinfilteration includes several advantages such as time and cost saving in comparison to other transient expression systems such as particle bombardment. This technique has been used in many experimental researches for example, studying foreign gene function (Chen et al., 2013), investigation of plant promoter expression (Liu et al., 2003), study of hypersensitivity responses (Palanichelvam et al., 2000) and gene silencing (Voinnet et al., 2003).

In this study, in order to evaluate in order to evaluate inducible efficiency of the MPI in a new background (tomato as a dicot model), in silico sequence MPI promoter analysis was first performed. Then transient expression of $G U S$ reporter gene was assessed using an agroinfiltereation system and qRT- PCR approach. The obtained results showed that MPI could be considered as an acceptable inducible promoter to generate dicot transgenic plants.

\section{Results and discussion}

It would be very convenient to use inducible or tissuespecific promoters in generating transgenic plants for reduction of damages as well as decrease in the amount of plant metabolic changes. Regarding this purpose, working efficiency of the wound-inducible MPI promoter in dicot plants (tomato as a model) was investigated by conducting in silico sequence analysis, histochemical GUS and qRT-PCR assays. The advantages of employing wound-inducible promoters over constitutive promoters are: 1) woundresponse is independent of plant age; and 2) the gene under control of wound-inducible promoter is induced in response to phytophagous insects attack and toxin (such as Cry), and does not produce and accumulate during plant development leading to energy saving (Breitler et al., 2004).

\section{In Silico detection of the various MPI promoter elements}

Computational prediction of promoter elements is an important approach to improve understanding of gene expression regulation. Before conducting an experiment, in silico sequence analysis actually help to design appropriate experiments. Based on our results, the length of sequenced
MPI region was 886 bp. After confirmation of the MPI sequence by BLASTn, TSS site was determined by using SOFTBERRY database following determination of +1 position at the nucleotide sequence 701 , and also TATA box sequence was found at -36bp upstream of TSS. Functions of different promoters is determined based on their cis elements (Hernandez-Garcia and Finer, 2014). Therefore, in the current study, PLANTCARE software was employed to determine wound inducible and other motifs of the MPI promoter (Fig. 2; Table 2). CAAT box, which is found to be at $-57 \mathrm{bp}$ upstream of TSS, is a binding site signal for RNA transcription factors (Ke et al., 1997). Four methyl jasmonate (MeJA) inducible motifs were identified and subsequently classified into two groups; First group, CGTCA motif which is located at 215 upstream and 185 downstream of TSS site, and second group, TGACG motif was identified at -215 and + 162 of TSS in complementary strand. G-box (CACGTG), which is involved in light response, UV and abscisic acid (ABA) stimuli was predicted at $-640 \mathrm{bp}$ upstream of TSS (McKendree Jr and Ferl, 1992). MRE motif (5'-AACCTAA$3^{\prime}$ ) is considered as a recognition element for MYB transcription factor and is necessary for light responsiveness (Feldbrügge et al., 1997). This motif was determined at -699 nucleotide position. Two other motifs, which are involved in response to light, were identified at -450 (5'-TACGTG-3') and -64 (5'-CACGTC-3') of TSS. The GT1 (5'-GTTGTGAA$\left.3^{\prime}\right)$ and $\mathrm{H}$ (5'-ACCATTTTCACTC-3') motifs were recognized at -341 and $-347 \mathrm{bp}$ of TSS, respectively. These motifs are involved in light-mediated regulation (Hagen et al., 1999). Two TC-rich motifs were predicted in the MPI promoter at -603 (5'-ATTTTCTCCA-3') and -368 (5'ATTTTCTTCA-3') location involving in plant stress and defense responses. The LTR motif (5'-CCGAAA-3') at -283 is involved in low-temperature response. another report revealed that the LTR motifs regulate cold, drought as well as ABA related gene expression (Baker et al., 1994). Several $A C G T$ elements were found in MPI promoter, as well. In vivo assessment of transgenic plants have illustrated that these elements are necessary for maximal transcriptional activity (Foster et al., 1994). Several W-boxes were determined in the MPI promoter (Table 2). Results of a microarray-based study revealed that w-box is a common promoter element in a group of defense-related genes (Maleck et al., 2000), therefore, W-box could be an important cis-acting element for transcriptional regulation after pathogen attack. WRKY transcription factors can bind to W-box and enhance transcription of the related gene in secondary metabolite biosynthesis process, as well (Yu et al., 2001; Kumar et al., 2009; Yang et al., 2013). plants normally use several molecules such as jasmonate (Farmer and Ryan, 1990), ethylene (Donnell et al., 1996) and ABA (Pēna-Cortés et al., 1989) for activating of defense response through transcriptional activation of specific genes. It has been reported that MeJA and $\mathrm{ABA}$ can induce expression of genes through specific motifs, which are located in wound inducible promoters (Xu et al., 1993). Therefore, existence of jasmonate (JA), ethylene and ABA responsive elements suggests that probably the MPI has a good potential to be used as a wound-inducible promoter. JA (and its derivates MeJA) and ABA act as wound signals in response to mechanical wounding, as well (Hernandez-Garcia and Finer, 2014 ). Herbivore pests activate proteinase inhibitor gene through JA synthetic pathway. Therefore, plants may use expression induction of insecticidal related genes as a defense system. By sequence Alignment of MPI promoter isolated from cultivar 704 with the mpi gene sequence in NCBI (B73, accession number: X78988.2), Kimura 2-parameter (K2P) 
Table 1. The primer sequences designed for amplification of the MPI promoter designed by Oligo 7.

\begin{tabular}{lllll}
\hline $\begin{array}{l}\text { Primer } \\
\text { name }\end{array}$ & Primer sequence & $\Delta \mathrm{G}$ & bp & Annealing temperature \\
\hline F-MPI & 3'- AAGCTTTTTAGGTTCTACACAAAACCCTC - 5' & -9.4 & 29 & \\
R-MPI & 5'- TCTAGACCGGACCAGTTGACGA -3' & -8.1 & 22 & 65 \\
\hline
\end{tabular}

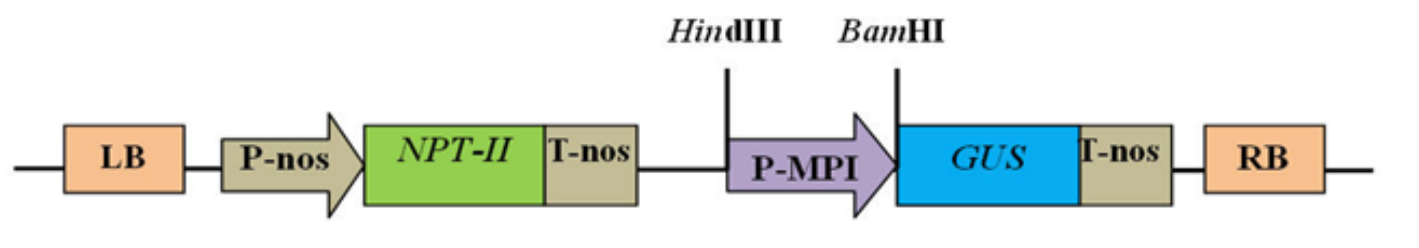

Fig 1. Shematic representation of the T-DNA cassette in the binary vector pBI:MPI:GUS. Abbrevation RB, right border; LB, left border; nptII, neomycin phosphotransferase II gene; P-nos, nopaline synthase promoter; T-nos, nopaline terminator;gus, betaglucuronidase gene; P-MPI, Maize Proteinase Inhibitor promoter which replaced for CaMV35S promoter.

Table 2. Cis-acting regulatory elements determined in the MPI promoter by PLANTCARE software.

\begin{tabular}{|c|c|c|c|c|}
\hline Element & $\begin{array}{l}\text { Sequenec } \\
\left(5^{\prime} \rightarrow 3^{\prime}\right)\end{array}$ & Position & Strand & Excepted function \\
\hline \multirow[t]{2}{*}{ AE-box } & AGAAACAA & -296 & + & Light responsive element \\
\hline & AGAAACAA & -228 & - & Light responsive element \\
\hline \multirow{6}{*}{ CAAT-box } & CAAAT & -603 & - & Cis-acting element in promoter and enhancer regions \\
\hline & CAAT & -388 & - & Cis-acting element in promoter and enhancer regions \\
\hline & CAATT & -406 & - & Cis-acting element in promoter and enhancer regions \\
\hline & CAAT & +43 & + & Cis-acting element in promoter and enhancer regions \\
\hline & CAAT & -405 & - & Cis-acting element in promoter and enhancer regions \\
\hline & CAAT & +113 & + & Cis-acting element in promoter and enhancer regions \\
\hline CAG-motif & GAAAGGCAGAC & +37 & - & Light responsive element \\
\hline CAT-box & GCCACT & -107 & - & Cis- acting regulatory element related to mersitem expression \\
\hline CCGTCC-box & CCGTCC & -638 & - & Cis- acting regulatory element related to mersitem expression \\
\hline CGTCA-motif & CGTCA & -215 & + & MeJA responsive element \\
\hline GT1-motif & GTGTGTGAA & -341 & - & Light responsive element \\
\hline H-box & ACCATTTTCACTC & -347 & + & Light responsive element \\
\hline LTR & CCGAAA & -283 & + & Cis-acting element involved in low-temperature responsiveness \\
\hline MBS & CAAGTG & +165 & + & MYB binding site involved in drought-inducibility \\
\hline MRE & AACCTAA & -699 & - & Light responsive element \\
\hline Skn1-motif & GTCAT & -428 & + & Cis-acting regulatory element required for endosperm expression \\
\hline TATC-box & TATCCCA & -162 & - & GA-responsive element \\
\hline \multirow[t]{2}{*}{ TC-rich repeat } & ATTTTCTCCA & -603 & + & Cis-acting element involved in defense and stress responsiveness \\
\hline & АТTTTCTTCA & -368 & + & Cis-acting element involved in defense and stress responsiveness \\
\hline TCT-motif & TCTTAC & -440 & - & Light responsive element \\
\hline
\end{tabular}




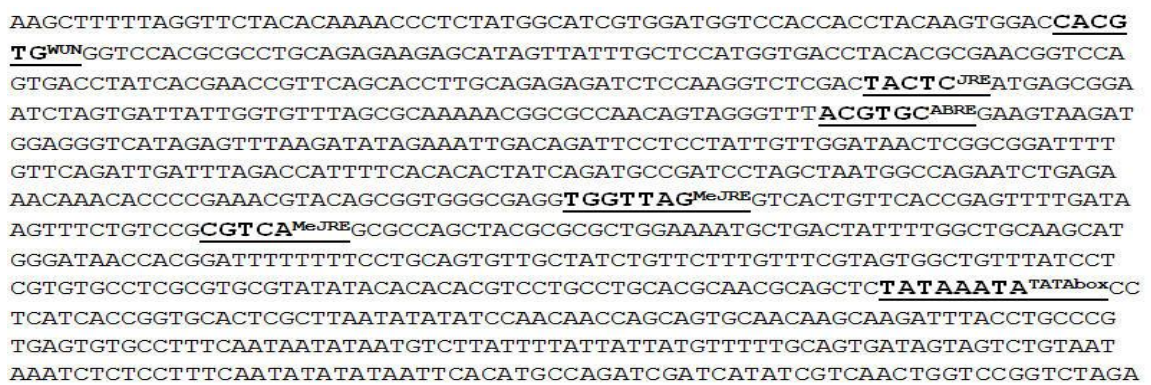

Fig 2. The nucleotides sequence of cloned MPI promoter from Zea mays L. cv. 704. This sequence has been deposited to GeneBank (Accession number: KP793074). The TATA box and wound inducible motifs are shown. The bold letters indicate some boxes which are induced by abcisic acid (ABRE), methyl jasmonate (MeJA), Wound (WUN) and jasmonate JRE). The PLANTCARE software has been use to identified the MPI promoter cis elements.

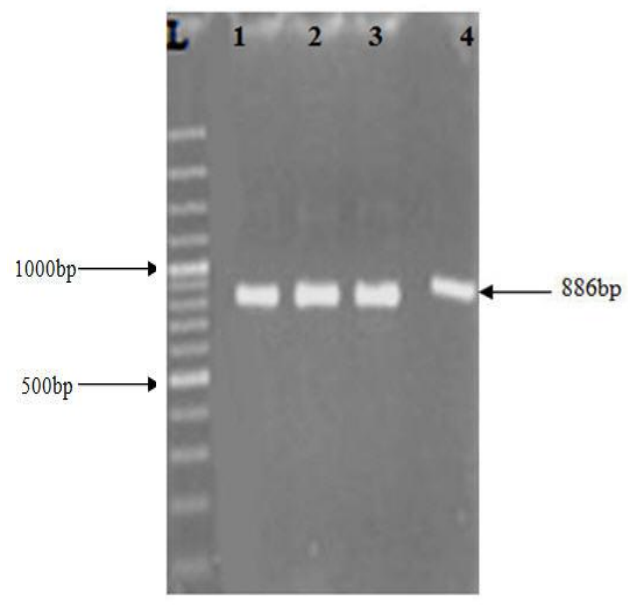

Fig 3. Confirmation of the presence of MPI promoter in several Agrobacterium strain AGL1 colonies by PCR. An 886 bp fragment of the MPI promoter (from Zea mays L. cv. 704) was amplified by PCR from the recombinant colonies. L) 1 Kb ladder. Lane 1-4 presents the transgenic lines.

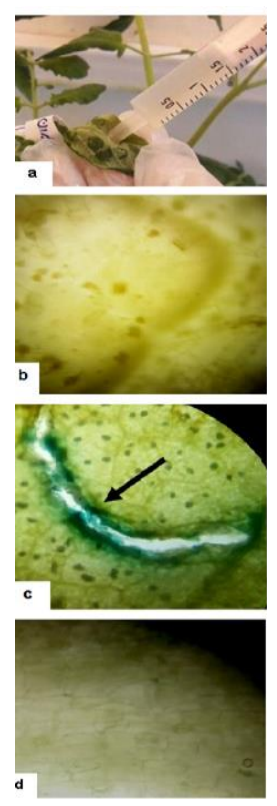

Fig 4. Agroinfilteration and Histochemical GUS assay. a) Injection of Agrobacterium suspension harboring the pBI:MPI:GUS plasmid into tomato leaf. b) Unwounded and c) Wounded leaves injected by the construct suspension MPI promoter (pBI:MPI:GUS); and d) negative control (injected by PBS buffer). The black arrow shows the wounded site. GUS has been expressed only at the wounded site (c). There was no GUS expression at a detectable level in unwounded leaves. 

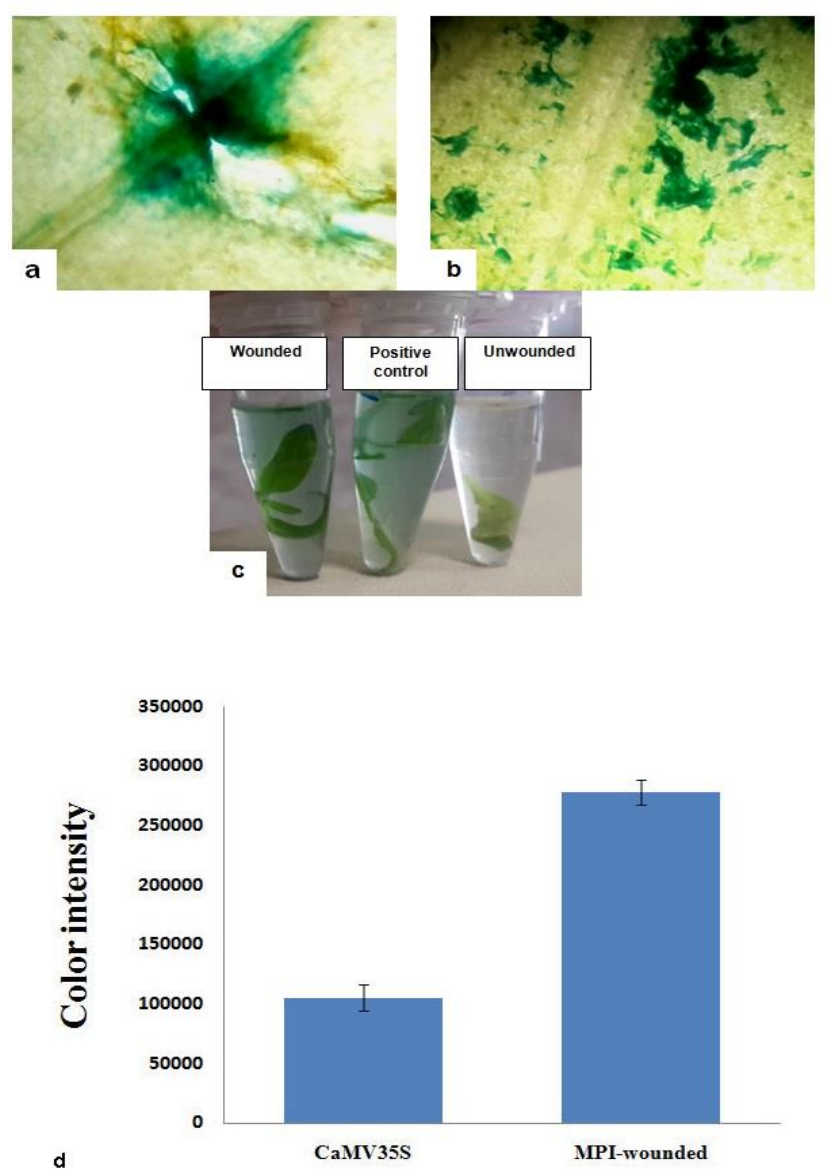

Fig 5. Histochemical GUS assay and comparison of color intensity using imageJ. a) Wounded sample containing the MPI promoter (pBI:MPI:GUS); b) Positive control using a constitutive promoter (pBI:35S:GUS) and c) Macroscopic comparisons of samples. As shown in the above figure, the color intensity of the MPI promoter (b) is approximately equal to that of constitutive CaMV35S promoter (a). The macroscopic assessment results consistent with the above findings. d) A comparison of the blue color intensity data obtained from GUS histochemical assay using imageJ revealed that the color intensity of MPI promoter is more than CaMV35S. Therefore, the MPI promoter has sufficient strength to express its downstream genes.

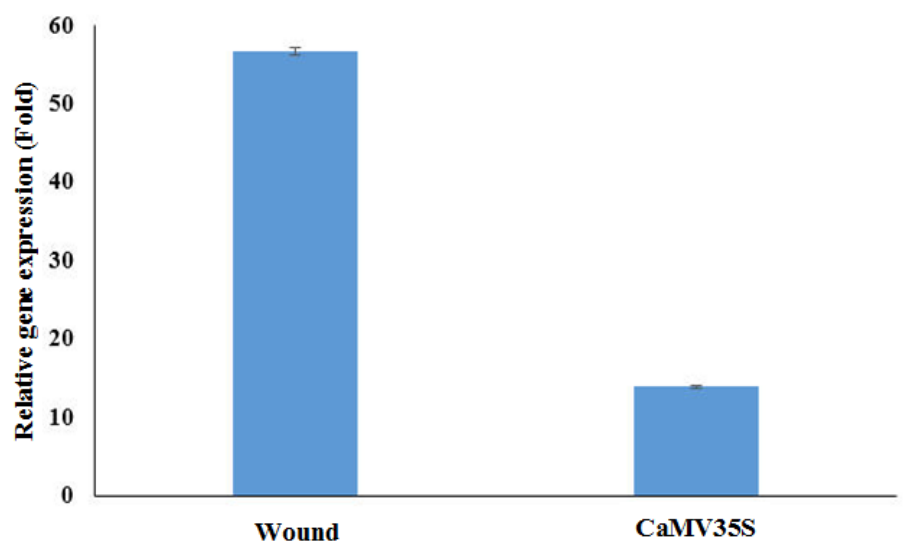

Fig 6. Quantitative measurement of relative expression of GUS gene in young and healthy leaves from one-month-old plants after 72 hours of agroinfiltration. The universal Actin gene was used as an internal reference gene. Each column calculated using $2^{-} \Delta \Delta \mathrm{Ct}$ formula, as mentioned in material method, with standard errors from three replicates. As shown in the figure, the expression level of GUS in leaves with the MPI promoter is more than CaMV35S. 
was calculated. K2P and gene diversity were 0.003 and $0.34 \%$, respectively. Three transition substitutions were found in the isolated MPI promoter at 26, 164 and 544 positions. These substitutions were not detected in wound inducible motifs. Based on the aforementioned in silico sequence analysis, the isolated MPI promoter probably can meet our goal to function as a wound-inducible promoter in plants. In order to verify the bioinformatic predictions, PBI:MPI:GUS was transferred into tomato leaves using agroinfilteration approach

\section{Confirmation of recombinant clones following agroinfilteration of tomato leaves}

Recombinant colonies containing the suitable segment (886bp) were identified (Fig. 3) based on colony PCR approach following transferring a single colony to LB medium containing kanamycin $(100 \mu \mathrm{g} / \mathrm{ml})$ to grow for 48 hours. The bacterial suspensions were injected into plant leaves by applying $2 \mathrm{ml}$ needleless syringe. After 72 hours, the injected leaves were collected for further analysis. Agroinfilteration is a rapid technique in order to introduce gene of interest into plant cells for a broad range of applications such as promoter investigation (Liu et al., 2003) and production of pharmaceutical proteins. The simplicity of syringe agroinfilteration allows further quick assessments. Different parameters such as OD and temperature can affect the efficiency of agroinfilteration. According to previous evaluations, the best bacterial suspension OD for injection of tomato leaves is 0.5 , and at $22-23^{\circ} \mathrm{C}$, high level of $G U S$ expression has been reported (Dillen et al., 1997; Yasmin and Debener, 2010). In this study, acetosyringone $(200 \mu \mathrm{M})$ was used to induce the vir genes. Phenolic compounds such as acetosyringone are required to increase the vir genes induction and improve Agrobacterium transformation efficiency (Hiei et al., 1994)

\section{Detection of GUS activity in wounded leaves}

Histochemically GUS activity assay was carried out on the injected leaf tissues, which have been agroinfilterated by Agrobacterium tumefaciens AGL1 strains harboring either pBI:MPI:GUS or pBI:35S:GUS. The related results demonstrated that induction of MPI promoter occurs only in wounded leaves, and no GUS activity (blue color) was detected in unwounded leaves harboring pBI:MPI:GUS (Fig . 4). No GUS staining was detected in any of the negative controls suggesting that our findings were not affected by environmental factors (Fig. 4). Moreover, GUS expression only occurs at the wounded leaf site (not the total leaf surface area), Therefore, genes under control of the MPI promoter are more probably expressed at the time and site of pest attack. These results are in agreement with the reports provided by Cordero et al. (1994) and Tamayo et al. (2000). Coredo et al. (1994) showed that the mpi mRNA accumulation was induced in response to fungal infection in maize embryos, while no mpi transcript was detected in maize unwounded tissues. In this regard, Tamayo et al. (2000) also revealed that MPI protein accumulation occurs in tissues adjacent to the wound created by Spodoptera litturalis in maize leaves (Tamayo et al., 2000). Consistent with our findings, Breitler et al. (2001) demonstrated that $-689 /+197$ region of $m p i$ gene is sufficient to express an insecticidal gene in transgenic rice to protect it against stem borer attack. Thus, the MPI promoter could be used to generate transgenic plants containing pest-resistant genes under control of this wound-inducible promoter. Interestingly, using these kinds of transgenic plants is more sensible due to energy saving and expressing the insecticidal proteins at the site of pest attack. Moreover, expression of insecticidal genes in healthy parts of those plants is lacking. Although insect resistance plants harboring cry genes under CaMV35S promoter are grown in several countries (Kumar et al., 2009). However, the most desired strategy is to express the insecticidal genes under a promoter that would express only at the site of feeding by larvae (Kumar et al., 2009). Thus driving cry genes under control MPI promoter could be a helpful way to enhance expression of these genes at the site of wounding when insects start feeding.

In this study, recombinant vector pBI: $35 \mathrm{~S}: G U S$ has been used as a positive control for pBI: MPI: GUS. As shown in figure 5, visual survey reveals that the strength of $M P I$ promoter is approximately equal to the constitutive CaMV35S promoter. For further analysis, image $\mathbf{J}$ program was applied to evaluate the GUS color intensity in wounded leaves. The color intensity was calculated based on the formula: Integrated Density - (Area of selected cell X Mean color of background readings). The background reading should be an area close to the site of interest. The results of color intensity assessment confirmed that the MPI promoter give higher color intensity (2.64 fold) compared to the CaMV35S (Figure 5). To date, just few promoters, which are the same or stronger than CaMV35S have been identified (Zhang et al., 2013). However, according to the results presented in this study, the activity and expression of MPI promoter is more than CaMV35S. The MPI promoter could be also a very useful promoter to generate such constructs containing insecticidal genes (different types of cry) just expressed once plants are being attacked by insect pests.

\section{Quantitative measurement of relative expression of GUS gene}

Relative gene expression analysis of GUS using qRT-PCR revealed that the transcript levels of GUS gene in the wounded leaves containing MPI promoter ( $p B I: M P I: G U S$ ) is 4.1 fold higher than the positive control wounded leaves containing 35S promoter ( $p B I: 35 S: G U S$ ) (Fig. 6). These findings are in agreement with the results of histochemical GUS assay. These results are also consistent with Breitler et al. (2001) in rice revealing that efficiency of MPI promoter in response to mechanical wounding induced 3-5 fold higher GUS activity in comparison to the constitutive promoter. Although, in contrast to $35 \mathrm{~S}$ (constitutive promoter), induction of MPI is only localized to the site of leaf wounding, the transcripts level of GUS under control of the MPI is higher than that of $35 \mathrm{~S}$. Therefore, it could be concluded that in the case of localized expression, MPI promoter is much stronger than CaMV35S. The MPI reaction to wounding is likely related to the wound responsive elements including MeJA and ABA motifs, and therefore inducible promoters provide precise regulation of transgene expression through external control (Hernandez-Garcia and Finer, 2014). Defense responsive promoters are necessary in plant biotechnology applications to develop resistant transgenic crops. Otherwise, the biosynthesis of abundant recombinant proteins under control of constitutive promoters can impact plant energy and subsequently reduction in yield and biomass (Hernandez-Garcia and Finer, 2014). Thus, there are some important reasons to develop inducible expression systems in crop plant biotechnology.

The main aim of this study was to assess the possible function of MPI promoter in a new plant background (tomato). The presented results showed that MPI promoter, 
which has been isolated from maize and subsequently transferred to tomato, could almost function in the same way in dicot plants as found in monocots (Breitler et al., 2001). Regardless of current study results, several plant promoters such as Wipl showed a different function in monocot and dicot plants. Wipl promoter originating from maize was not induced by wounding in transgenic tobacco plants (Zhang et al., 2013). Interestingly, our findings are in agreement with the results reported by $\mathrm{Xu}$ et al. (1993), who demonstrated that the pin2 wound-inducible promoter from potato conferred the same expression of GUS gene in transgenic rice plants.

\section{Materials and methods}

\section{Plant materials and MPI promoter isolation}

Seeds of Zea mays L. cv. 704 and Lycopersicon esculentum Mill. cv. CH were provided by Pakan Bazr Seed Company (Isfahan, Iran). The maize seeds were grown for 15days in the lab growth chamber with a photoperiod 16/8 hours light/dark at $23^{\circ} \mathrm{C}$ and $70 \%$ relative humidity following genomic DNA extraction using the modified CTAB method (Murray and Thompson, 1980). The quality and quantity of DNA has been determined by $1 \%$ agarose gel electrophoresis and nanodrop spechtrophotometer (Thermo Scientific, USA). In order to design specific primers to amplify MPI promoter, first sequence of Zea mays L. (inbred line B73) mpi gene was obtained from GeneBank (Accession number: X78988.2), and then software Oligo 5.0 (Molecular Biology insights, Inc.,cascade, CO, USA) (Table 1) were used. PCR reaction containing the final volume $15 \mu \mathrm{l}$ was prepared as follows: $1.5 \mu$ of $10 \mathrm{X}$ PCR buffer, $2 \mathrm{mM} \mathrm{MgCl} 2,1 \mathrm{U}$ of LONG PCR Enzyme Mix (Thermo Fisher Scientific), $0.2 \mathrm{mM}$ dNTPs, 0.3 $\mu \mathrm{M}$ of each primer and approximately $20 \mathrm{ng}$ of genomic DNA. The LONG PCR Enzyme Mix has a proofreading activity and mostly generates 3 '-dA tailed PCR products. The thermocycler program (BioRad, USA) was conducted at " 5 $\min$ at $95^{\circ} \mathrm{C}$ followed by 30 cycles of $1 \min 94^{\circ} \mathrm{C}, 1 \mathrm{~min}$ $65^{\circ} \mathrm{C}$ and $1 \mathrm{~min}$ at $72^{\circ} \mathrm{C}$, with a final extension of $10 \mathrm{~min}$ at $72^{\circ} \mathrm{C} "$. The right size PCR products were extracted from the agarose gel using gel extraction kit (Thermo Fisher Scientific) and then cloned into pTZ57R/T vector (Thermo Fisher Scientific), following transformation of Escherichia coli MC1061 using cloning kit based on manufacturer instructions. Plasmids containing the mpi fragment were purified by plasmid extraction kit (Thermo Fisher Scientific) according to the manufacturer's instructions. Colony PCR following digestion by BamHI and HindIII (Thermo Fisher Scientific) were performed for screening of colonies containing the desired insertions. Confirmed colony was subsequently sequenced (Bioneer Inc., South Korea) and then deposited in GeneBank (Accession number: KP793074). Therefore, nucleotide sequences of the MPI promoter of Zea mays L. cv. 704 were identified and confirmed afterward by using BLASTn (Altschul et al., 1990) tool in NCBI.

\section{In silico sequence analysis of the MPI promoter}

In order to calculate pairwise distance of sequenced MPI promoter to compare with the mpi gene sequence in NCBI (B73, accession number: X78988.2), the K2P model (Kimura 2-parameter), which calculates distance based on transitional and transversional substitution rates by using MEGA ver. 5, was employed (Tamura et al., 2011). Transition, transversion, substitution and InDel were calculated by ARLEQUIN version 3.1 (Excoffier and Lischer, 2010). The percentage of genetic diversity was obtained by using the number of different nucleotides to the total number of nucleotides for each region. In order to determinate the transcriptional start site (TSS) of the MPI, SOFTBERRY database (http://www.softberry.com) was used. Searching for cisacting elements was carried out using PLANTCARE (Lescot et al., 2002).

\section{PBI:MPI:GUS construction}

Binary vector pBI121 (pBI: 35S: GUS) has been employed for the agroinfiltration performance. Both plasmids pBI121 and $\mathrm{pTZ} 57 \mathrm{R} / \mathrm{T}$ (containing the confirmed MPI fragment) were extracted using plasmid extraction kit (Thermo Fisher Scientific) following digestion by BamHI and HindIII (Thermo Fisher Scientific). Then the MPI promoter were extracted from agarose gel using gel extraction kit (Thermo Fisher Scientific) and subsequently cloned into pBI121 (Fig. 1). Colony PCR and restriction enzyme digestion approaches were subsequently used for screening colonies containing PBI:MPI:GUS vector.

\section{Agro-infilteration}

The PBI:MPI:GUS and pBI: 35S: GUS recombinant plasmids were transferred into competent cells of Agrobacterium tumefaciens strain AGL1 by micropulser electroporator (Biorad, USA), following bacterial growth at $28^{\circ} \mathrm{C}$ for 72 hours. Colony PCR approach was used to confirm colonies with interested recombinant vector. A confirmed single recombinant colony was transferred to LB medium containing kanamycin $(100 \mu \mathrm{g} / \mathrm{ml})$, ampicilin $(100 \mu \mathrm{g} / \mathrm{ml})$ and rifampcin $(50 \mu \mathrm{g} / \mathrm{ml})$ and subsequently incubated at $28^{\circ} \mathrm{C}$ and $250 \mathrm{rpm}$ for 48 hours in darkness. The Agrobacterium cells were harvested at $\mathrm{OD}_{600} 0.5$ by centrifugation at 5000 rpm for $10 \mathrm{~min}$ and resuspended in PBS buffer ( $\mathrm{pH}$ 7.4) plus $200 \mu \mathrm{M}$ acetosyringone and subsequently injected into plant leaves by use of $2 \mathrm{ml}$ needleless syringes. PBS buffer was also injected into plant leaves as negative control. Therefore, the following samples including injected leaves by either pBI: 35S: GUS (positive control) or pBI:MPI:GUS, unwounded leaves, and injected negative control leaves by PBS buffer was evaluated. Each assessment was carried out on three young and healthy separated leaves from one-monthold single plants. After injection, plants were incubated at $23^{\circ} \mathrm{C}$ in darkness for 72 hours. These plants were used for histochemical GUS assay.

\section{Histochemical GUS activity assay}

In order to assay promoter function and efficiency in transgenic leaves, 24 hours after the agroinfiltration, the injected leaves were wounded by forceps, and other leaves and control plants remained intact. After 72 hours, wounded, unwounded, negative and positive controls were collected following histochemical GUS activity assay according to the Jefferson et al. (1987). Then, plant leaf disks were decolorized by $70 \%$ ethanol at $50^{\circ} \mathrm{C}$ and were investigated by means of an optical microscope. The color intensity was calculated by image J software (Rasband, 1997).

\section{RNA isolation and quantitative real-time PCR (qRT-PCR)}

The injected leaves have been collected 72 hours after agroinfiltration, and total RNA was isolated from injected leaves (wounded and positive control leaves) using RNXPlus (Sinaclon, Iran) following the manufacturer's 
instruction. Complementary DNA (cDNA) was synthesized using cDNA synthesis kit (Pishgam, Iran) according to the manufacturer instruction. The qRT-PCR was performed using universal GUS specific forward 5'TCACAGCCAAAAGCCAGA $-3^{\prime}$ and reverse 5'AAGCGTAAGGGTAATGCGAG $-3^{\prime}$ primers. Universal Actin (as an endogenous control gene) forward 5'GCTCCTCAGTTGAGAAGAGC-3' and reverse 5'CCTTCCTGATATCCACGTCAC-3' primers were used. The qRT- PCR reactions were performed on a LightCycler-96 real-time PCR. Each reaction was performed in triplicate using the following program: $5 \mathrm{~min}$ at $95^{\circ} \mathrm{C}$ followed by 35 cycles of $95{ }^{\circ} \mathrm{C}$ for $20 \mathrm{~s}, 60{ }^{\circ} \mathrm{C}$ for $25 \mathrm{~s}, 72{ }^{\circ} \mathrm{C}$ for $25 \mathrm{~s}$ with a single fluorescent measurement and melting curve program (60-95 with a heating rate of 0.1 per second and continuous fluorescent measurement). Cycle threshold $\left(C_{\mathrm{t}}\right)$ values were determined for each sample and comparative CT method $\left(\Delta \Delta C_{\mathrm{t}}\right)$ was used to determine relative quantification of $G U S$ transcript (Livak and Schmittgen, 2001).

\section{Conclusion}

In order to bring the paper in a final touchdown, in silico sequence analysis of the MPI promoter resulted in identification of cis-acting elements related to the woundresponsive motifs. The GUS histochemical activity assay and qRT-PCR findings indicated that the MPI promoter can work as a wound-inducible promoter the induction of which occurs only in the wounded site of tomato leaves. Therefore, the MPI promoter could also be expressed in dicot plants as occurred in monocot plants. Based on the obtained results, the $M P I$ promoter can be very useful in plant engineering to develop insect-resistant transgenic plants containing strong wound-inducible promoter.

\section{Acknowledgments}

This project was jointly funded by University of Guilan, and the Iranian National Science Foundation of Islamic Republic of Iran (Grant under No: 93033715).

\section{References}

Altschul SF, Gish W, Miller W, Myers EW, Lipman DJ (1990) Basic local alignment search tool. J Mol Biol. 215(3):403-410.

Andow D, Ives A (2002) Monitoring and adaptive resistance management. Ecol Appl. 12(5):1378-1390.

Baker SS, Wilhelm KS, Thomashow MF (1994) The 5'region of Arabidopsis thaliana cor15a has cis-acting elements that confer cold-, drought- and ABA-regulated gene expression. Plant Mol Biol. 24(5):701-713.

Bates SL, Zhao J-Z, Roush RT, Shelton AM (2005) Insect resistance management in GM crops: past, present and future. Nat Biotechnol. 23(1):57-62.

Breitler JC, Cordero MJ, Royer M, Meynard D, San Segundo B, Guiderdoni E (2001) The $-689 /+197$ region of the maize protease inhibitor gene directs high level, woundinducible expression of the cry1B gene which protects transgenic rice plants from stemborer attack. Mol Breed. 7(4):259-274.

Breitler JC, Vassal JM, Del Mar Catala M, Meynard D, Marfà V, Melé E, Royer M, Murillo I, San Segundo B, Guiderdoni E (2004) Bt rice harbouring cry genes controlled by a constitutive or wound-inducible promoter: protection and transgene expression under Mediterranean field conditions. Plant Biotechnol J. 2(5):417-430.
Chen Q, Lai H, Hurtado J, Stahnke J, Leuzinger K, Dent M (2013) Agroinfiltration as an effective and scalable strategy of gene delivery for production of pharmaceutical proteins. Adv Tech Biol Med. 1:103.

Conner AJ, Glare TR, Nap JP (2003) The release of genetically modified crops into the environment. Plant $\mathrm{J}$. 33(1):19-46.

Cordero MJ, Raventós D, Segundo B (1994) Expression of a maize proteinase inhibitor gene is induced in response to wounding and fungal infection: systemic wound-response of a monocot gene. Plant J. 6(2):141-150.

Dillen W, Clercq J, Kapila J, Zambre M, Montagu M, Angenon G (1997) The effect of temperature on Agrobacterium tumefaciens-mediated gene transfer to plants. Plant J. 12(6):1459-1463.

Donnell P, Calvert C, Atzorn R, Wasternack C (1996) Ethylene as a signal mediating the wound response of tomato plants. Science. 274(5294):1914.

Excoffier L, Lischer HE (2010) Arlequin suite ver 3.5: a new series of programs to perform population genetics analyses under Linux and Windows. Mol Ecol Resour. 10(3):564567.

Farmer EE, Ryan CA (1990) Interplant communication: airborne methyl jasmonate induces synthesis of proteinase inhibitors in plant leaves. P Natl Acad Sci USA. 87(19):7713-7716.

Feldbrügge M, Sprenger M, Hahlbrock K, Weisshaar B (1997) PcMYB1, a novel plant protein containing a DNA binding domain with one MYB repeat, interacts in vivo with a light regulatory promoter unit. Plant J. 11: 10791093.

Foster R, Izawa T, Chua N (1994) Plant bZIP proteins gather at ACGT elements. FASEB J. 8(2):192-200.

Gassmann AJ, Petzold-Maxwell JL, Keweshan RS , Dunbar MW (2011) Field-evolved resistance to Bt maize by western corn rootworm. PLoS One. 6(7):e22629.

Hagen FK, Hazes B, Raffo R, Tabak LA (1999) StructureFunction Analysis of the UDP-N-acetyl-d-galactosamine: PolypeptideN-acetylgalactosaminyltransferase essential residue lie in a predicted active site cleff resembling a lactose repressor fold. J Biol Chem. 274: 6797-6803.

Hartl M, Giri AP, Kaur H, Baldwin IT (2011) The multiple functions of plant serine protease inhibitors: defense against herbivores and beyond. Plant Signal Behav. 6(7):1009-1011.

Hernandez-Garcia CM, Finer JJ (2014) Identification and validation of promoters and cis-acting regulatory elements. Plant Sci. 217:109-119.

Hiei Y, Ohta S, Komari T, Kumashiro T (1994) Efficient transformation of rice (Oryza sativa L.) mediated by Agrobacterium and sequence analysis of the boundaries of the T-DNA. Plant J. 6(2):271-282.

Jamal F, Pandey PK, Singh D and Khan M (2013) Serine protease inhibitors in plants: nature's arsenal crafted for insect predators. Phytochem Rev. 12(1):1-34.

Jefferson AR, Kavanagh AT, Bevan WM (1987) GUS fusions: ,B-glucuronidase as a sensitive and versatile gene fusion marker in higher plants. EMBO J. 6(13): 3901-3907.

Ke J, Choi JK, Smith M, Horner HT, Nikolau BJ, Wurtele ES (1997) Structure of the CACl gene and in situ characterization of its expression (the arabidopsis thaliana gene coding for the biotin-containing subunit of the plastidic acetyl-coenzyme a carboxylase). Plant Physiol. 113(2):357-365.

Kim S, Kim C, Li W, Kim T, Li Y, Zaidi MA, Altosaar I (2008) Inheritance and field performance of transgenic 
Korean $\mathrm{Bt}$ rice lines resistant to rice yellow stem borer. Euphytica. 164(3):829-839.

Kuiper HA, Kleter GA, Noteborn HP, Kok EJ (2001) Assessment of the food safety issues related to genetically modified foods. Plant J. 27(6):503-528.

Kumar M, Shukla AK, Singh H, Tuli R (2009) Development of insect resistant transgenic cotton lines expressing crylEC gene from an insect bite and wound inducible promoter. J Biotechnol. 140(3):143-148.

Lescot M, Déhais P, Thijs G, Marchal K, Moreau Y, Van de Peer Y, Rouzé P, Rombauts S (2002) PlantCARE, a database of plant cis-acting regulatory elements and a portal to tools for in silico analysis of promoter sequences. Nucleic Acids Res. 30(1):325-327.

Liu Z-Z, Wang JL, Huang X, Xu WH, Liu ZM, Fang RX (2003) The promoter of a rice glycine-rich protein gene, Osgrp-2, confers vascular-specific expression in transgenic plants. Planta. 216(5):824-833.

Livak KJ, Schmittgen TD (2001) Analysis of relative gene expression data using real-time quantitative PCR and the 2 (-Delta Delta C (T) method. Methods. 25:402-408.

Maleck K, Levine A, Eulgem T, Morgan A, Schmid J, Lawton KA, Dangl JL, Dietrich RA (2000) The transcriptome of Arabidopsis thaliana during systemic acquired resistance. Nat Genet. 26: 403-410.

McKendree Jr WL, Ferl RJ (1992) Functional elements of the Arabidopsis Adh promoter include the G-box. Plant Mol Biol. 19(5):859-862.

Murray M, Thompson WF (1980) Rapid isolation of high molecular weight plant DNA. Nucleic Acids Res. 8(19):4321-4326.

Palanichelvam K, Cole AB, Shababi M, Schoelz JE (2000) Agroinfiltration of Cauliflower mosaic virus gene VI elicits hypersensitive response in Nicotiana species. Mol Plant Microbe In. 13(11):1275-1279.

Pēna-Cortés H, Sánchez-Serrano JJ, Mertens R, Willmitzer L, Prat S (1989) Abscisic acid is involved in the woundinduced expression of the proteinase inhibitor II gene in potato and tomato. P Natl Acad Sci USA. 86(24):98519855.

Rasband W (1997) ImageJ, US National Institutes of Health, Bethesda, Maryland, USA

Shelton AM, Zhao J-Z, Roush RT (2002) Economic, ecological, food safety, and social consequences of the deployment of Bt transgenic plants. Annu Rev Entomol. 47(1):845-881.

Stotz HU, Kroymann J, Mitchell-Olds T (1999) Plant-insect interactions. Curr Opin Plant Biol. 2(4):268-272.

Tabashnik BE, Brévault T, Carrière Y (2013) Insect resistance to Bt crops: lessons from the first billion acres. Nat Biotechnol. 31(6):510-521.

Tamayo MC, Rufat M, Bravo JM, San Segundo B (2000) Accumulation of a maize proteinase inhibitor in response to wounding and insect feeding, and characterization of its activity toward digestive proteinases of Spodoptera littoralis larvae. Planta. 211(1):62-71.
Tamura K, Peterson D, Peterson N, Stecher G, Nei M, Kumar S (2011) MEGA5: molecular evolutionary genetics analysis using maximum likelihood, evolutionary distance, and maximum parsimony methods. Mol Biol Evol. 28(10):2731-2739.

Van den Berg J, Hilbeck A, Bøhn T (2013) Pest resistance to $C r y 1 A b$ Bt maize: Field resistance, contributing factors and lessons from South Africa. Crop Prot. 54:154-160.

Voinnet O, Rivas S, Mestre P, Baulcombe D (2003) Retracted: An enhanced transient expression system in plants based on suppression of gene silencing by the p19 protein of tomato bushy stunt virus. Plant J. 33(5):949-956.

Xu D, McElroy D, Thornburg RW, Wu R (1993) Systemic induction of a potato pin 2 promoter by wounding, methyl iasmonate, and abscisic acid in transgenic rice plants. Plant Mol Biol. 22(4):573-588.

Yang Z, Patra B, Li R, Pattanaik S, Yuan L (2013) Promoter analysis reveals cis-regulatory motifs associated with the expression of the WRKY transcription factor CrWRKY1 in Catharanthus roseus. Planta. 238(6):1039-1049.

Yasmin A, Debener T (2010) Transient gene expression in rose petals via Agrobacterium infiltration. Plant Cell Tiss Org. 102(2):245-250.

Yu D, Chen C, Chen Z (2001) Evidence for an important role of WRKY DNA binding proteins in the regulation of NPR1 gene expression. Plant Cell. 13(7):1527-1540.

Zhang S, Lian Y, Liu Y, Wang X, Liu Y, Wang G (2013) Characterization of a maize Wip1 promoter in transgenic plants. Int J Mol Sci. 14(12):23872-23892. 